\title{
From Research Methods to Methodical Researcher: Making Use of the Student Voice Towards a More Comprehensive Module Evaluation
}

\author{
Michael Hast \\ School of Management and Social Sciences, St Mary's University, Twickenham \\ Waldegrave Road, Twickenham TW1 4SX, United Kingdom \\ Tel: +440208240 4366 E-mail: michael.hast@smuc.ac.uk
}

Received: October 23, 2014 Accepted: November 5, 2014 Published: November 6, 2014

doi:10.5296/jet.v2i1.6479 URL: http://dx.doi.org/10.5296/jet.v2i1.6479

\begin{abstract}
It is not uncommon for undergraduate students to feel aversion towards research methods teaching. This does not change the fact that research methods play a key role in their education. Targeting module design is imperative to ensure success. However, end-of-module student evaluations may provide a false sense of security regarding satisfaction and learnt knowledge. In order to approach module design more effectively it may instead be necessary to view module evaluations from a delayed perspective. The present study addressed student perceptions of a second year social science research methods module and the related final year dissertation module, thereby offering two perspectives on research methods. Both preand post-dissertation students participated in a survey evaluating their theoretical and practical knowledge as well as issues surrounding confidence in carrying out independent research. The key findings demonstrate that end-of-module evaluations do appear to give good insight into research methods teaching but that post-dissertation students provided critical input that could not be gained from end-of-module evaluations alone. As a whole, the findings demonstrate that making more comprehensive use of different student perspectives may be essential to ensuring appropriate teaching design and, as a result, student satisfaction and success as independent researchers.
\end{abstract}

Keywords: Module evaluations, research methods, dissertations, student voice

\section{Introduction}

"Learning is a process of interaction between what is known and what is to be learnt" (Pritchard, 2009, p. 104). Helping students identify this interaction in their own learning is 
crucial in the development of higher education modules, both in terms of content and teaching approach. This may be of particular importance in the broad field of 'research' teaching about research methods, carrying out independent research projects, and acquiring generic research skills. Critically, the foundation of research needs to show sufficient student inclusion into the academic research world to maximise overall student experiences and success in the long run. There is a heightened appreciation for higher education students as being actively engaged in their learning processes, both as active learners and as indicators of teaching success. Central to this is working with students to identify whether contents are appropriate or where changes need to be made. A key challenge that needs to be worked with in this process is student engagement (Ahlfeldt, Mehta, \& Sellnow, 2005). This paper intends to deal with making use of enhanced student feedback to improve research methods teaching.

\subsection{Students as Researchers}

Research forms an integral part of most undergraduate degree programmes, with final year dissertations frequently involving independent collection, analysis and reporting of primary data by students (Rammell, 2006; Todd, Bannister, \& Clegg, 2004). At a minimum, learning how to become a researcher should cater for analysis skills relevant to the wider learning process across different modules since it enables students to engage more clearly with different texts that are directly based on active research (Ryan, Saunders, Rainsford, \& Thompson, 2014). However, there is general acknowledgement that skills developed through such activities also promote skills such as time management, organisation and self-directed learning are frequently highlighted (Allin, 2010; Huggins, Jenkins, \& Scurry, 2007; Stefani, Clarke, \& Littlejohn, 2000), and such development is seen as "central to professional life in the twenty-first century" (Brew, 2006, p. 7). Such wide-reaching implications highlight the significance of ensuring success in the process of training students to become researchers.

Yet what can be noted is that students often do not feel sufficiently prepared when it comes to carrying out independent research projects (Allin, 2010); a key measure of their ability to act as researchers. Such lack of preparation may leave students feeling excluded from the academic world of research, or not feeling as a part of it (Zamorski, 2000). This is a critical issue as confidence and self-perceived competence play a significant role in undergraduate students' academic achievement and their resulting experiences of higher education (Cassidy, 2012; Diseth, Pallesen, Brunborg, \& Larsen, 2010; Ferla, Valcke, \& Schuvten, 2010; Nicholson, Putwain, Connors, \& Hornby-Atkinson, 2013). Students also see research as an important personal discovery experience (Hunter, Laursen, \& Seymour, 2007). Together, these issues illustrate the long-term importance of taking students more seriously as active researchers and regarding them more as a part of the researcher community in higher education. Research preparation prior to final year research activities is therefore an important issue to address - particularly in the social sciences, where a range of paradigms and methods is available, and where students need to be aware of this range (Healey, 2005).

\subsection{Research Methods Teaching}

Crucial to successful research methods education is the provision of sense of inclusion into the community of research. This can be challenging, especially in the social sciences, where 
dissatisfaction with relevant training is no uncommon feature and where students frequently display aversion to the subject (Ryan et al., 2014). Effective teaching would need to therefore take into account both the issue of inclusion and aversion - which are not mutually exclusive - in order to provide students with beneficial experiences of research methods. A main reason for the insufficient preparation prior to dissertations may be because of an emphasis on "method acting" (Ryan et al., 2014, p. 85) approaches to teaching about research - teaching practical research in a theoretical and abstract manner - rather than allowing for hands on experiences (Benson \& Blackman, 2003; Fallon, Walsh, \& Prendergast, 2013). It is, in fact, frequently suggested that students do need to have hands on experience with research - data collection, analysis and presentation - in order to gain the appropriate confidence in becoming independent researchers so as to make the learning experiences more meaningful to them (e.g. Bignold, 2003; Edwards, Jones, Wapstra, \& Richardson, 2007; Gawel \& Greengrove, 2005; McGrath \& MacEwan, 2011; Petress, 2008; Smith, Sheppard, Johnson, \& Johnson, 2005; Ward, Bennett, \& Bauer, 2003; Zamorski, 2002).

Curriculum structures in higher education do need to reflect actual research (Jenkins \& Healey, 2011). Teaching and research do not have to be in opposition, and teaching should be enhanced by research activities (Brew, 2006). But teaching research methods should also be about actively incorporating students into this world of research, into the practice of a community, not keeping them at arms' length from research (Jenkins \& Healey, 2011). As such, understanding how students feel about research methods teaching and understanding what they feel to be necessary for inclusion in such a community is essential. Understanding how students feel about such a vital part of a course is important, since student attitudes towards research methods affect course enrolment, persistence, achievement and course climate (Harlow, Burkholder, \& Morrow, 2002; Hilton, Schau, \& Olsen, 2004). Success in a course, in turn, depends on motivations, course contents and how these contents are taught (Helmke, 2009; Mutz \& Daniel, 2013). And as a whole, research, for undergraduates, is generally associated with higher levels of student satisfaction and with their perceptions of generic skill development (Bauer \& Bennett, 2003; Hathaway, Nagda, \& Gregerman, 2002; Ishiyama, 2002; Seymour, Hunter, Laursen, \& Deantoni, 2004; Willison \& O'Regan, 2007). Focusing on appropriate content and teaching approaches is therefore highly essential.

\subsection{Making Use of the Student Voice}

One key approach to evaluating teaching success and appropriateness is through end-of-module evaluations completed by students. Most university courses make use of some form of student evaluation to assess satisfaction with course contents, teaching quality and their overall experience (Winchester \& Winchester, 2012). This kind of information is seen as extremely important and plays a significant role in quality assurance processes (Leckey \& Neill, 2001). However, end-of-course module evaluations risk a loss in meaningful input into module design due to decreased motivation to correctly fill in such evaluation forms (Winchester \& Winchester, 2012). This may be exemplified by recent student evaluations of the research methods module that will be evaluated in the study to follow. Around two thirds of students agreed or strongly agreed with being overall satisfied with the module, and similar numbers felt the teaching was at the right pitch (with practically all other students 
scoring the pitch as 'slightly below' or 'slightly above'). Given the general literature surrounding student aversion towards research methods, these results could be misconstrued and lead to a lack of necessary changes in course content or structure, as they may provide a false sense of security for those responsible for designing the module. What are these students actually satisfied with?

For lecturers, it is crucial that students are not just enjoying the teaching but that they are receiving appropriate educational benefits; that they are, in this case, able to confidently carry out their own research projects. Yet it can be very difficult to understand whether students feel they are receiving the right kind of lecture content, given the satisfaction ratings. Although at the end of a module students may know what they have learnt, they may not fully understand what they need to know for dissertations until they encounter that stage. Admittedly, this may hold true for any module, but for many modules the applications may only come post-degree. For research methods the applications are almost immediate and within the degree, which heightens the importance for those designing the modules. This raises the question of how valid research methods students' evaluations of research methods really are. In fact, there is an increased call for incorporating student views in higher education curriculum development and change, which extends beyond simply relying on module feedback about the teaching that takes place (Cooper, 2012; Dunne \& Zandstra, 2011; Kay, Dunne, \& Hutchinson, 2010; McCulloch, 2009; O’Neill \& McMahon, 2012; Ramsden, 2008a, b; Robinson, 2012). Instead, students should be given a stronger voice in order to identify issues and needs. While concern has been expressed about viewing students too much as consumers due to recent policy changes and thereby reducing education to a commodity (Furedi, 2009), working together to achieve success and satisfaction may be an ideal compromise benefiting both students and teaching staff (Sandover, Partridge, Dunne, \& Burkill, 2012).

As a result the study outlined here aimed to evaluate research methods teaching from multiple student perspectives to maximise views on research methods teaching. Specifically, it addressed the issue of preparation and confidence in relation to carrying out research by evaluating student views at both pre- and post-dissertation stages. In doing so, it is hoped that a clearer understanding can be gained as to how students can best be integrated into a community of research and to help them progress from research methods students to methodical researchers.

\section{Method}

\subsection{Participants}

A total of 86 undergraduate students from a Higher Education Institution in the Greater London area were invited to take part in this study. Of these, 49 students had just completed their second year of an undergraduate social science degree course during which they had been registered for a research methods module. The remaining 37 students had just submitted their undergraduate research project dissertation for the same course and had previously taken the research methods module. Students were invited to participate via email. Response rates, most likely due to having reached the end of the academic year and due to the time 
constraints in which the study was carried out, were low; only seven second year students and four final year students responded. ${ }^{1}$

\subsection{Design, Materials and Procedure}

Two surveys were developed, presented as a Word document. The surveys incorporated six-point Likert scales ('strongly disagree', 'disagree', 'slightly disagree', 'slightly agree', 'agree', 'strongly agree') and open-ended response opportunities. Both surveys contained the same questions but these were rephrased across the surveys to reflect the respondent group, differentiating between those students who were due to embark on their final year dissertation and those who had just completed the dissertation. The survey consisted of two sections. The first section addressed the research methods module, requiring the students to evaluate their perceptions of the module approach, the activities used in teaching, and the assessment to evaluate their skills. The second section addressed the dissertation, requiring the students to evaluate their pre- or post-conceptions of the dissertation in specific relation to the research methods module.

\section{Results}

Discussed below are the outcomes of the surveys returned by the students. The outcomes focus on the theoretical understanding of research methods, the practical understanding of research methods, the assessment used, the dissertation, and the aspect of research community inclusion. Specifically, findings from the two student groups are compared and contrasted to present a fuller picture of student module evaluation.

\subsection{Theoretical Understanding of Research Methods}

Similarly to the module evaluation form that informed the present study, the second-year students generally expressed satisfaction with how research methods theory was explained to them (14\% agreed, $86 \%$ slightly agreed). They generally felt well prepared from a theoretical perspective (71\% agreed, $29 \%$ slightly agreed). Students expressed being 'more aware of the different methods for researching and their strengths and weaknesses'. The survey results from the final year students reflected similar views, showing equally high agreement rates about the research methods module and making similar additional comments such as having a heightened awareness of the 'various ways that data could be collected'. The similarity between both viewpoints would indicate that direct end-of-module evaluations seem to be useful in addressing this particular aspect of teaching. However, having the advantage of knowing how helpful the research methods theory was towards the dissertation the final year students also noted that it would have been helpful to have 'examples of different data collection that had been used in real research projects'. While it is not sufficiently clear at this point whether this is a request for "method acting" (cf. Ryan et al., 2014, p. 85) or actual practical examples, there is a clear need for some incorporation of more actual research elements.

\footnotetext{
${ }^{1}$ The research presented here was completed towards a postgraduate certificate in Higher Education, which limited immediate opportunities for further data collection.
} 


\subsection{Practical Understanding of Research Methods}

While the theoretical perceptions of the teaching were largely positive and mostly corresponded between student perspectives, the survey results assessing the practical aspects, on the other hand, showed more disagreement. Most of the second year students did not feel well prepared in terms of practical preparation (57\% disagreed, $29 \%$ slightly disagreed), and confidence in developing research questions was not high ( $71 \%$ slightly disagreed). Some students acknowledged positives, such as being 'more aware now of the problems surrounding research such as ethics', yet many expressed a lack of awareness of how to actively carry out research when in the field. Instead, they proposed incorporating 'real research practice' as well as 'relevant examples e.g. of past students ... and the problems they had, how they overcame them'. This seems to be somewhat clearer than the viewpoint offered in the final year students' theoretical evaluation and does indicate a need for research examples that go beyond method acting. However, the final year students were somewhat more positive about the research methods module in terms of practical preparation, generally showing a positive perception (25\% agreed, 50\% slightly agreed). However, one crucial comment made here was that 'there could have been more of an emphasis to pilot research methods'. Again it is clear, then, that a key issue is the lack of practical elements to relate the theory to as well as the development of confidence in approaching independent research in the final year. So although viewpoints differed in terms of satisfaction - which may be due to some form of post-dissertation reflection process - the comments again indicate similar needs in research methods teaching.

\subsection{Assessing Understanding of Research Methods}

The research methods students' assessment comprised a research proposal, in which they were required to provide their ideas for a project and discuss the methods they would use; as such it is a very theoretical piece. Given the lack of practical elements here - unlike a research report - it seemed important to address the usefulness of this assessment tool. The second year students did feel that the research proposal was an appropriate assessment $(100 \%$ slightly agreed) and expressed appreciation for the usefulness of seeing 'the similar layout between the proposal and the dissertation and how to approach such a piece of work'. In agreement, the final year students also found that the proposal was a helpful way to approach their dissertation as it 'prepared a foundation ... to work from'. Nonetheless in both cases these comments simply highlight the usefulness in terms of how to approach the dissertation as a whole piece - 'it was obviously helpful in terms of getting a rough idea of what had to be done in the third year'. Yet at the same time most of the students could not acknowledge having acquired skills on collecting data (29\% disagreed, $57 \%$ slightly disagreed), on analysing and evaluating data ( $86 \%$ disagreed, $14 \%$ slightly disagreed), or on presenting data ( $86 \%$ disagreed, $14 \%$ slightly disagreed). On the whole, therefore, the theoretical side of the module was again seemingly well covered but it is evident that the practical aspects of carrying out research are not covered sufficiently to give students the confidence and competence they may need. 


\subsection{The Dissertation}

In general, the second year students expressed that they felt prepared to start the dissertation but the main issue raised was confidence in approaching their research $(71 \%$ slightly disagreed, $14 \%$ disagreed). It is unclear here what the confidence refers to in particular. However, the additional information provided by the third-year students, whose survey results reflected a similar perception of confidence prior to embarking on their own research projects, may help shed light on this matter. It was seen as 'a good experience writing a dissertation', but there were several issues raised in relation to working on the research projects. The only relevant positive comment made was that one student found it easy to relate 'the theory ... to the appropriate responses from participants' - once again emphasising the strength of the theoretical underpinnings of research. On the other hand, students commented on several practical issues where they required additional help or which they struggled with. The range of the comments, too, highlights the severity of the issue. Students found it difficult 'producing the right questions' for their project to begin with. They also noted issues relating to the evaluation of their research, finding it hard to 'transcribe the data and find meaning'. It is clearly not just a matter of gaining practical experience of methods of data collection but also of how to ask questions and how to evaluate the outcomes of these methods. This may have knock-on effects, as further reflected in the students' perceptions of writing the dissertation. Here they noted that 'the methodology section was quite daunting' and commented on the difficulty of finding 'appropriate structure to communicate ... findings'. Taken as a whole, the findings from this section may be most crucial in determining the usefulness of research methods teaching, as end-of-module evaluations would be very unlikely to capture such comments since students at that point will not have had the experience of carrying out their dissertation project.

\subsection{Learning From the Learned: the Role of Peers for Community Inclusion}

The role of experience provided by teaching staff is not only highlighted in traditional educational approaches in general but in research education in particular (Allin, 2010; Boud \& Lee, 2005; Chang, 2005; Healey \& Jenkins, 2009; Johnson, Herd, \& Tisdall, 2002). However, while lecturers contributing to the teaching of research methods have experience of carrying out research projects this experience may be too advanced for student purposes. This difference in skill level may thus not be entirely appropriate for advancing confidence and self-perceived competence. One possible factor to support student inclusion into the academic research community was, instead, the involvement of dissertation students in the research methods teaching. Indeed, one aspect that recurred frequently throughout the surveys from both pre- and post-dissertation students was the potential help that more experienced students could offer in terms of practical issues in carrying out research. This is particularly beneficial when these peers are only slightly advanced in what they can share, reducing the distance between student research and 'real' large-scale research projects. The more immediately advanced students would be the final year students in the process of applying their recently gained knowledge. Demonstrating their skills may help highlight issues that need to be tackled at a more realistic level and may make self-determined goals more achievable to students. This is clearly reflected in the survey outcomes, too. Students felt it would be 
helpful to see what their advanced peers have done and how they have dealt with any problems they encountered. As a result, all of the second year students felt they would have benefited from brief research project presentations by final year dissertation students. It is, however, unfortunate that the final year students expressed a lack of confidence to present their work, despite feeling proud of their achievement. This could act as a barrier to establishing a more coherent research community among students, but may have been due not having received their dissertation results at the time of the survey. At the same time they did expressed a willingness to share more general advice in relation to working on a dissertation, such as time management. Building confidence in the ability to carry out research may have a knock-on effect, though, with future students being more confident in presenting their research.

\section{Discussion}

Taken as a whole, the findings obtained from the present study are a clear indication of the limitations of end-of-module evaluations. Acting on the limited insight from such evaluations may not be sufficient in ensuring student success. Certain areas of the survey addressing teaching showed strong similarities between the two sets of students, such as the theoretical underpinnings and the usefulness of the assessment. At the same time other areas clearly demonstrated that views either differed slightly or that final year students were able to give more detailed insight into the teaching of the module. Without these additional views any changes to module content or teaching approaches would be appropriate but would still be restricted to the limited possible input from end-of-module evaluations. The implications are, then, that appropriate module design in higher education needs to take into account the wider perspective to ensure students are gaining the knowledge and skills necessary for success.

However, these implications here are not only restricted to research methods and dissertation modules, which did serve as a good example due to their relationship with each other. The findings are equally relevant to any modules that are directly linked to one another in some manner. For instance, a range of undergraduate university courses offers study skills programmes in their first years, where students are familiarised with academic writing, referencing, or team work - skills that have direct relevance for subsequent university work and where foundational success would therefore be crucial (see e.g. Coughlan \& Swift, 2011; Elander, 2003; Groves, Leflay, Smith, Bowd, \& Barber, 2013; Rees \& Wilkinson, 2008). In such cases it may therefore be similarly suitable to make use of feedback from students in their second or final year to gain a fuller module evaluation picture. Most importantly, it is about ensuring a comprehensive evaluation that makes as much use of the student voice as possible.

\subsection{Limitations}

Although the surveys provided good insight into different perspectives, there are issues surrounding the depth of this insight. Interviews might have been preferable to address this issue but given the time constraints within which the evaluation was conducted the surveys were restricted to a small time window between completion of dissertations and leaving university. As such, the findings here should be viewed as initial insight only, and interviews, 
such as focus groups, might possibly provide more detailed accounts. Relatedly, response rates were clearly affected here, which was not unexpected given the nature of survey completions (cf. Bryman, 2012; Cohen, Manion, \& Morrison, 2013). As such, the insight provided was not particularly strong. It had been hoped that their own recent experiences of research methods and their knowledge of survey limitations might encourage stronger response rates. However, given the issue of time, as noted above, it is difficult to state with certainty that interviews would have provided more information, given that a very specific sample set was required here. A further limitation here is that the study compared two sets of students who would have had two different experiences, given that the dissertation students had taken research methods the previous year and were therefore essentially commenting on a different module. However, given that course structures changed minimally between the two years the information provided by the final year students still showed significant insight into research methods teaching as a direct experience of completing a dissertation and should therefore still be viewed as relevant to addressing module design.

\subsection{Future Research}

Given the limitations outlined above, more detailed evaluations may wish to focus on incorporating interviews to establish more insight. One approach to doing this may be by following dissertation students through the process of their research project, and addressing aspects of the evaluation at certain key stages in this process. Where relevant, the evaluation could focus on the literature review, the methodology, or the findings and analysis section in each instance. A further aspect of future research may want to address the issue of confidence in presenting own research to foster a sense of community among students. One opportunity to develop such a sense of community, given the lack of confidence expressed by the dissertation students in the present survey, would be to incorporate research experience from postgraduate students. This would reduce issues surrounding the potentially too wide discrepancy between student research expectations and the 'real' research world. Future investigations would do well to address the impact this might have on students' confidence in approaching their own research and this might, in turn, impact on success of research methods teaching.

\section{Conclusion}

Despite some limitations having been identified, the overall work presented here is a clear demonstration of the heightened insight offered by students at later stages and how this could potentially affect module design. In particular, the study suggests that widening the scope may enhance immediate research methods training success, which should in turn lead undergraduates from research methods to becoming more methodical researchers.

\section{References}

Ahlfeldt, S., Mehta, S., \& Sellnow, T. (2005). Measurement and analysis of student engagement in university classes where varying levels of PBL methods of instruction are in use. Higher Education Research and Development, 24, 5-20. http://dx.doi.org/10.1080/0729 436052000318541 
Allin, L. (2010). Linking research, teaching and learning within the discipline: Evaluating student learning through "real life" research in sports development. Journal of Hospitality, Leisure, Sport and Tourism Education, 9, 92-100. http://dx.doi.org/10.3794/johlste.91.261

Bauer, K., \& Bennett, J. (2003). Alumni perceptions used to assess undergraduate research experience. The Journal of Higher Education, 74, 210-230. http://dx.doi.org/10.1353/jhe. 2003.0011

Benson, A., \& Blackman, D. (2003). Can research methods ever be interesting? Active Learning in Higher Education, 4, 39-55. http://dx.doi.org/10.1177/1469787403004001004

Bignold, S. (2003). A review of linking teaching and research in the health sciences and practice disciplines. Retrieved April 04, 2014, from http://www.health.heacademy.ac.uk/ lenses/publications/m10100.html

Brew, A. (2006). Research and teaching: Beyond the divide. New York, NY: Palgrave Macmillan.

Bryman, A. (2012). Social research methods. Oxford: Oxford University Press.

Cassidy, S. (2012). Exploring individual differences as determining factors in student academic achievement in higher education. Studies in Higher Education, 37, 793-810. http://dx.doi.org/10.1080/03075079.2010.545948

Cohen, L., Manion, L., \& Morrison, K. (2013). Research methods in education. London: Routledge.

Cooper, B. (2012). Embedding student-led change in the curriculum. Retrieved June 28, 2014, from

http://www.heacademy.ac.uk/assets/documents/stem-conference/STEMLearningandTeaching Issues1/Barrie_Cooper.pdf

Coughlan, J., \& Swift, S. (2011). Student and tutor perceptions of learning and teaching on a first - year study skills module in a university computing department. Educational Studies, 37, 529-539. http://dx.doi.org/10.1080/03055698.2010.539698

Diseth, A., Pallesen, S., Brunborg, G. S., \& Larsen, S. (2010). Academic achievement among first semester undergraduate psychology students: The role of course experience, effort, motives and learning strategies. Higher Education, 59, 335-352. http://dx.doi.org/10.1007/ s10734-009-9251-8

Dunne, E., \& Zandstra, R. (2011). Students as change agents: New ways of engaging with learning and teaching in higher education. Exeter: University of Exeter.

Edwards, A., Jones, S. M., Wapstra, E., \& Richardson, A. M. M. (2007). Engaging students through authentic research experiences. UniServe Science Teaching and Learning Research Proceedings, 168-171.

Edwards, D., \& Thatcher, J. (2004). A student-centred tutor-led approach to teaching research methods. Journal of Further and Higher Education, 28, 195-206. http://dx.doi.org/10.1080/ 
0309877042000206750

Elander, J. (2003). A discipline-based undergraduate skills module. Psychology Learning and Teaching, 3, 48-55.

Fallon, E., Walsh, S., \& Prendergast, T. (2013). An activity-based approach to the learning and teaching of research methods: Measuring student engagement and learning, Irish Journal of Academic Practice, 2(1), Article 2.

Ferla, J., Valcke, M., \& Schuvten, G. (2010). Judgments of self-perceived academic competence and their differential impact on students' achievement motivation, learning approach, and academic performance. European Journal of Psychology of Education, 25, 519-536. http://dx.doi.org/10.1007/s10212-010-0030-9

Furedi, F. (2009, June 04). Now is the age of the discontented. Times Higher Education. Retrieved June 28, 2014, from http://www.timeshighereducation.co.uk/406780.article

Gawel, J. E., \& Greengrove, C. L. (2005). Designing undergraduate research experiences for nontraditional student learning at sea. Journal of Geoscience Education, 53, 31-36.

Groves, M., Leflay, K., Smith, J., Bowd, B., \& Barber, A. (2013). Encouraging the development of higher-level study skills using an experiential learning framework. Teaching in Higher Education, 18, 545-556. http://dx.doi.org/10.1080/13562517.2012.753052

Harlow, L. L., Burkholder, G. L., \& Morrow, J. A. (2002). Evaluating attitude, skill, and performance in a learning quantitative methods course: A structural modeling approach. Structural Equation Modeling, 9, 413-430. http://dx.doi.org/10.1207/S15328007SEM0903_6

Hathaway, R., Nagda, B., \& Gregerman, S. (2002). The relationship of undergraduate research participation to graduate and professional education pursuit: An empirical study. Journal of College Student Development, 43, 614-631.

Healey, M. (2005). Linking research and teaching to benefit student learning. Journal of Geography in Higher Education, 29, 183-201. http://dx.doi.org/10.1080/03098260500130387

Healey, M., \& Jenkins, A. (2009). Linking discipline-based research and teaching through mainstreaming undergraduate research and inquiry. Retrieved April 05, 2014, from http://www2.warwick.ac.uk/fac/cross_fac/iatl/cetl/resources/linking_discipline-based_researc h_and_teaching_through...pdf

Helmke, A. (2009). Unterrichtsqualität und Lehrerprofessionalität [Quality of instruction and teacher professionalism]. Selze-Velber: Kallmeyer.

Hilton, S. C., Schau, C., \& Olsen, J. A. (2004). Survey of attitude toward statistics: Factor structure invariance by gender and by administration time. Structural Equation Modeling, 11, 92-109. http://dx.doi.org/10.1207/S15328007SEM1101_7

Huggins, R., Jenkins, A., \& Scurry, D. (2007). Developing undergraduate research at Oxford Brookes University: Recommendations and models for future development. Retrieved April 04, 2014, from http://www2.warwick.ac.uk/fac/cross_fac/iatl/cetl/resources/developing_ug_ 
research_at_brookes.pdf

Hunter, A.-B., Laursen, S. L., \& Seymour, E. (2007). Becoming a scientist: The role of undergraduate research in students' cognitive, personal, and professional development. Science Education, 91, 36-74. http://dx.doi.org/10.1002/sce.20173

Ishiyama, J. (2002). Does early participation in undergraduate research benefit social science and humanities students? College Student Journal, 36, 380-386.

Jenkins, A., \& Healey, M. (2011). Navigating between teaching, learning and inquiry: Developing students as researchers. The International HETL Review, 1, 35-43.

Kay, J., Dunne, E., \& Hutchinson, J. (2010). Rethinking the values of higher education students as change agents? Bristol: The Quality Assurance Agency for Higher Education.

Leckey, J., \& Neill, N. (2001). Quantifying quality: The importance of student feedback. Quality in Higher Education, 7, 19-32. http://dx.doi.org/10.1080/13538320120045058

McCulloch, A. (2009). The student as co-producer: Learning from public administration about the student-university relationship. Studies in Higher Education, 34, 171-183. http://dx.doi.org/10.1080/03075070802562857

McGrath, J. R., \& MacEwan, G. (2011). Linking pedagogical practices of activity-based teaching. The International Journal of Interdisciplinary Social Sciences, 6, 261-274.

Mutz, R., \& Daniel, H.-D. (2013). University and student segmentation: Multilevel latent-class analysis of students' attitudes towards research methods and statistics. British Journal of Educational Psychology, 83, 280-304. http://dx.doi.org/10.1111/ j.2044-8279.2011.02062.x

Nicholson, L., Putwain, D., Connors, L., \& Hornby-Atkinson, P. (2013). The key to successful achievement as an undergraduate student: Confidence and realistic expectations? Studies in Higher Education, 38, 285-298. http://dx.doi.org/10.1080/03075079.2011.585710

O’Neill, G., \& McMahon, S. (2012). Giving student groups a stronger voice: Using participatory research and action (PRA) to initiate change to a curriculum. Innovations in Education and Teaching International, 2, 161-171. http://dx.doi.org/10.1080/14703297. 2012.677656

Petress, K. (2008). What is meant by “active learning"? Education, 128, 566-569.

Pritchard, A. (2009). Ways of learning: Learning theories and learning styles in the classroom. Oxford: Routledge.

Rammell, B. (2006, October). Innovations: Exploring research-based learning. Paper presented at the University of Warwick Conference, Warwick, UK.

Ramsden, P. (2008a). Higher education: Put students first. The Journal, 14. Retrieved June 28, 2014, from http://www.journal-online.co.uk/article/5131-higher-education-put-students-first

Ramsden, P. (2008b). The future of higher education teaching and the student experience. 
Retrieved June 28, 2014, from http://www.heacademy.ac.uk/resources/detail/consultations/ paulramsden_teaching_and_student_experience

Rees, A., \& Wilkinson, M. (2008). Scientific communication skills: The transition from further education to higher education in the UK. Journal of College Teaching \& Learning, 5, $33-40$.

Robinson, C. (2012). Student engagement: What does this mean in practice in the context of higher education institutions? Journal of Applied Research in Higher Education, 4, 94-108.

Ryan, M., Saunders, C., Rainsford, E., \& Thompson, E. (2014). Improving research methods teaching and learning in politics and international relations: A 'reality show' approach. Learning and Teaching in Politics and International Studies, 34, 85-97. http://dx.doi.org/10.1111/1467-9256.12020

Sandover, S., Partridge, L., Dunne, E., \& Burkill, S. (2012). Undergraduate researchers change learning and teaching: A case study in Australia and the United Kingdom. CUR Quarterly, 33, 33-39.

Seymour, E., Hunter, A., Laursen, S., \& Deantoni, T. (2004). Establishing the benefits of research experiences for undergraduates in the sciences: First findings from a three-year study. Science Education, 88, 493-534. http://dx.doi.org/10.1002/sce.10131

Shevlin, M., Banyard, P., Davies, M., \& Griffiths, M. (2000). The validity of student evaluation of teaching in higher education: Love me, love my lectures? Assessment \& Evaluation in Higher Education, 25, 397-405. http://dx.doi.org/10.1080/713611436

Smith, K. A., Sheppard, S. D., Johnson, D. W., \& Johnson, R. T. (2005). Pedagogies of engagement: Classroom-based practices. Journal of Engineering Education, 94, 87-101. http://dx.doi.org/10.1002/j.2168-9830.2005.tb00831.x

Stefani, L., Clarke, J., \& Littlejohn, A. (2000). Developing a student-centred approach to reflective learning. Innovations in Higher Education and Training International, 37, 163-171. http://dx.doi.org/10.1080/13558000050034529

Todd, M., Bannister, P., \& Clegg, S. (2004). Independent inquiry and the undergraduate dissertation: Perceptions and experiences of final-year social science students. Assessment \& Evaluation in Higher Education, 29, 335-355. http://dx.doi.org/10.1080/02602930420 00188285

Ward, C., Bennett, J., \& Bauer, K. (2003). Content analysis of undergraduate research student evaluations. Retrieved April 04, 2014, from http:/www.udel.edu/RAIRE/Content.pdf Willison, J., \& O’Regan, K. (2007). Commonly known, commonly not known, totally unknown: A framework for students becoming researchers. Higher Education Research and Development, 26, 393-409. http://dx.doi.org/10.1080/07294360701658609

Winchester, M., \& Winchester, T. M. (2012). If you build it will they come? Exploring the student perspective of weekly student evaluations of teaching. Assessment \& Evaluation in 
Higher Education, 37, 671-682. http://dx.doi.org/10.1080/02602938.2011.563278

Zamorski, B. (2000). Research-led teaching and learning in higher education. Norwich: Centre for Applied Research in Education, University of East Anglia.

Zamorski, B. (2002). What do students think about research? Exchange: Linking Teaching and Research, 3, 21-22.

\section{Copyright Disclaimer}

Copyright reserved by the author(s).

This article is an open-access article distributed under the terms and conditions of the Creative Commons Attribution license (http://creativecommons.org/licenses/by/3.0/). 